\title{
The Application of Electronic Information Technology in Electric Power Automation System
}

\author{
Ruidong Li \\ Jinhua Polytechnic, Jinhua, Zhejiang, 321017, China
}

Keywords: Application, Electronic Information Technology, Electric Power Automation System

\begin{abstract}
With the development of Chinese economy and the large-scale transformation of power systems, power system automation is getting higher and higher. Power system automation mainly covers three areas, namely, scheduling automation, substation automation and distribution network automation. The development of Chinese electric power automation system is closely related to the development of power grid infrastructure, computer hardware and software technology and electronic communication technology. Based on the reality of power system automation in China, this paper expounds the application of information technology in power automation system and discusses its future development direction.
\end{abstract}

\section{Introduction}

With the development of society, people's living standards are increasing and people pay more attention to the safety and reliability of power supply system. Due to the rapid development of Chinese economy, the power system has undergone large-scale transformation and the degree of automation of power systems is getting higher and higher. The power automation system uses modern electronic information technology to monitor the operation data of the power system. Power station operators can monitor the system through real-time control of the operation of the power system, remote control, according to its operating conditions quickly and accurately determine the system failure and data analysis.

Electric power automation system is widely used, involving a wide range of social daily life to be used to generate and transmission of electricity. The extensive use of power automation systems, the power system put forward more stringent requirements, making the development of the power system more difficult. In order to meet the social requirements, improve the working efficiency of the power system staff and reduce the difficulty of the work, a series of automated systems using electronic information technology in power system, such as relay protection system, on-line monitoring system and automatic control system, are studied. The use of these advanced technologies, you can clearly show the detailed operation of the power system to help staff quickly troubleshoot problems, making the power supply system more secure and reliable. Electronic information technology is an indispensable part of the electric power automation system, which belongs to the core content of the electric power automation system and plays a key role in the development of the electric power automation system.

\section{The Connotation of Electronic Automation System}

Electronic automation system to electronic information technology, automation and control technology and other related technologies, based on power generation, transmission, substation and electricity and other modules integrated together in the complex structure, thus achieving the entire power grid automation monitoring and management, for the safe and stable operation of the power system has laid a good foundation. At present, the power automation system as a flexible system platform, not only has the function of system software upgrades, but also has a certain degree of openness, that can be web browsing, query and other functions, and electronic information equipment is the realization of electronic automation system provides hardware and software. Firstly, the hardware part of the electronic automation system mainly collects the telemetry and telemetry in the power grid, and adjusts the relevant parameters by adjusting the relevant commands, 
and then adjusts the corresponding parameters of the equipment operation. Secondly, the software of the electronic automation system is the power generation control, power generation plans and other related purposes of management. In view of this, on the basis of modern electronic information technology, the electronic automation system has completed the remote monitoring of the whole power system. In view of this, electronic information technology in the power automation system plays a very important role.

\section{Status of Electric Power Automation System}

With the continuous development of power systems, the degree of automation of power systems has been greatly improved. Specifically, the power automation system mainly refers to the various devices arranged in the power system, such as measuring small instruments, control equipment, monitoring devices and so on. In the power system, the signal transmission and data exchange between the various parts, so as to ensure the integrity of the power system to monitor, in order to maintain its good running state, so that the power system operation and power supply security is guaranteed.

In the current power automation system which has been able to meet the practical application requirements. At the same time with a sound coordination control function, a higher degree of intelligence and integration, development status and development trend is more stable. In today's society, people pay more attention to the application of electronic information technology in the power automation system. In the process of monitoring and controlling the power system, gradually replaced by closed-loop control of the original open-loop control, while low-voltage equipment to replace the past high voltage system. For example, high voltage is converted to a low voltage prior to monitoring, thereby further improving the reliability and safety of the power system. In the past, most of the power system contains a lot of separate equipment components, in the monitoring and maintenance, the need to consume a lot of manpower, material and financial resources. In the current many power system integration system, the effective integration of the power system, so as to its better monitoring and control and data collection. In addition, the power system function has also undergone a certain change in the past and a single function is now more and more diversified. In addition, in the power system, the equipment gradually tended to be digital and diversified, further improving the device performance of the practicality, economy and flexibility. It can be seen in the current power system which is gradually moving towards the direction of the power automation system, and constantly improve the power system of intelligent, excellent, but also have a more complete and comprehensive function. In the future development of power automation system, it should increase the application of electronic information technology, and continuously improve the performance of the system efficiency, economic and practicality and security and stability, and the introduction of advanced management information systems and other human management model can continue to promote and promote the development of power automation systems and progress.

\section{Application of Electronic Information Technology in Electric Power Automation System}

Distribution Network Automation. Through the use of automatic control technology, communication technology, electronic technology, computer technology, the use of high-performance power distribution equipment, to achieve the distribution network automation. In order to achieve intelligent online or offline monitoring and management, to better ensure the distribution network of the economy, reliability, efficiency, security, so that the distribution network to maintain a good running state. In the distribution network which, including distribution transformers, cables, overhead lines and other equipment, in the entire power system which has an important role. In the power automation system, the application of distribution network automation technology can provide a new protection configuration program, so as to better protect the operation of the distribution network security. In the distribution network automation technology, mainly includes the feeder automation, equipment management automation, distribution network analysis 
automation, information analysis automation, cartography automation. Through the full application of electronic information technology, greatly improve the automation of the distribution network.

Substation Automation. Since 1990, the application of electronic information technology in substation automation system has become a hot issue in the power industry. Especially in recent years, with the deepening of power grid reform, Chinese substation automation system has made great progress, and after a long period of scientific research, electronic information technology has become an important means to promote power automation management. At present, in the process of applying electronic information technology, mainly through computer intelligence equipment as the basis, by reviewing the computer data interface, and the relevant data statistics and storage, especially for some difficult to analyze the data, and then continue to improve the power system digital level. In addition, in the substation automation construction process, you can use the automation equipment to replace the conventional equipment and instrumentation and relay protection devices, has reached the purpose of efficient and stable substation operation. In short, the electronic information technology in the substation automation construction has a broad development platform.

After the production of electricity, in order to transport to the user, you need to upgrade to high voltage. In order to complete this task, you need to make full use of substations. In the substation, the main equipment, including transformers, switches and so on. In which the application of substation automation technology, which can make the power transmission of the reliability and safety of better to better protect, thereby enhancing the performance of power automation systems. Optimized the secondary equipment of the intelligent substation, the equipment running status of the substation can be monitored in real time, thus forming an efficient automatic on-line monitoring system. Through the application of these technologies, the reliability, safety and stability of the substation operation are greatly improved, and the maintenance cost of the substation is reduced and the overall efficiency of the power system is improved.

Grid Dispatching Automation. With the continuous development of power automation system, the economic and practicality of power system and safety and reliability have also been higher guarantee. For the power system on-line monitoring, data collection and other functions, power grid dispatching automation has a very important role. As an important part of the electric power automation system, the power grid dispatching automation mainly includes the computer network system of the control center, the large shielding display, the workstation, the power station within the dispatching area, the server, the printing equipment, the subordinate power grid dispatching control center, the substation terminal equipment and so on. For the stable and safe operation of power grid dispatching, grid dispatching automation plays an important role in solving the problem of rational distribution of electrical energy. In the power grid dispatching automation technology, mainly based on the computer-based control system and technology, including equipment monitoring, estimating equipment status, control automatic power generation, sub-line operation safety, forecast system load, power grid economic scheduling and other technologies. In the power automation system which uses power grid dispatching automation, can effectively enhance the power system management level, to better ensure the operation of the power system economy, reliability, security and stability, thereby enhancing the quality of power supply.

\section{The Development Prospects of the Electronic Information Technology in the Power Automation System}

At present, the electronic information technology in the power automation system has been widely concerned, and has been a great application, but at the same time, in the development of electronic information technology, there are some problems: first, whether the electronic information equipment and Power automation equipment can be compatible. With the advent of microcomputers, a variety of microcomputer products continue to emit, and gradually become the direction of development of power automation systems. However, the structure of the power automation system is very complex, the environment is also very harsh, which will make microcomputer-type products in the phenomenon of refusal, especially when the computer crash situation, and even bring a huge 
economy loss. Moreover, a variety of electronic high-tech mushroomed, take the image information technology, in some cases, the power system on the image information technology analysis and understanding of the function has a high demand, then you need to help electronic visual technology to achieve the understanding of the image analysis, and intelligent processing, and thus ensure the effective operation of the power automation system.

\section{Conclusion}

In summary, in the process of sustainable development of the power industry, electronic information technology with a unique advantage and function occupies a very important position in the power automation system. In addition, the organic combination of computer technology and electronic information technology promote the continuous improvement of power automation system, achieve efficient and safe operation, and thus meet the broad masses of the people's electricity requirements.

\section{References}

[1] Application of Electronic Information Technology in Electronic Automation System [J]. Electronic Technology and Software Engineering, 2015, 9 (12): 48-50.

[2] Geng Nan. Electronic information technology and power automation system development[J]. Electronic production, 2013, 12 (09): 121-123.

[3] Liu Cheng. Analysis of electronic information technology in power automation system in the effective application[J]. Chinese new technology and new products, 2013, 24 (20): 45-46.

[4] Bao Xi, Jiao Shaohua, Qin Lijun. Distribution of the status quo and future[J]. Electric Age, 2002, (3):157-159

[5] Yang Yang. Scheduling automation power application software in the application of power grid[J]. Yunnan Electric Power Technology, 2008, (1):58-61 